\section{Soil chronosequences shed light on the silicon soil-plant cycle}

As soils age, geochemical weathering becomes less important for supplying silicon to the biosphere while terrestrial vegetation plays a greater role. Felix de Tombeur and Jean-Thomas Cornelis of the to study two rare due soil chronosequences spanning 2 millin Australia to study two rare dune soil chronosequences spanning 2 million years. Their findings show a nonlinear response of plant-available silicon to long-term soil formation, and that the retention of silicon by plants in old and silicon-depleted soils sustains its terrestrial cycling.

fter oxygen, silicon is the second-most abundant the carbonate-silicate cycle). As part of the carbon cycle, the weathering global silica cycle is closely linked
with the carbon cycle also known as processes transform silicate rocks into bicarbonate ions that precipt carbonates, that sediment into ocean

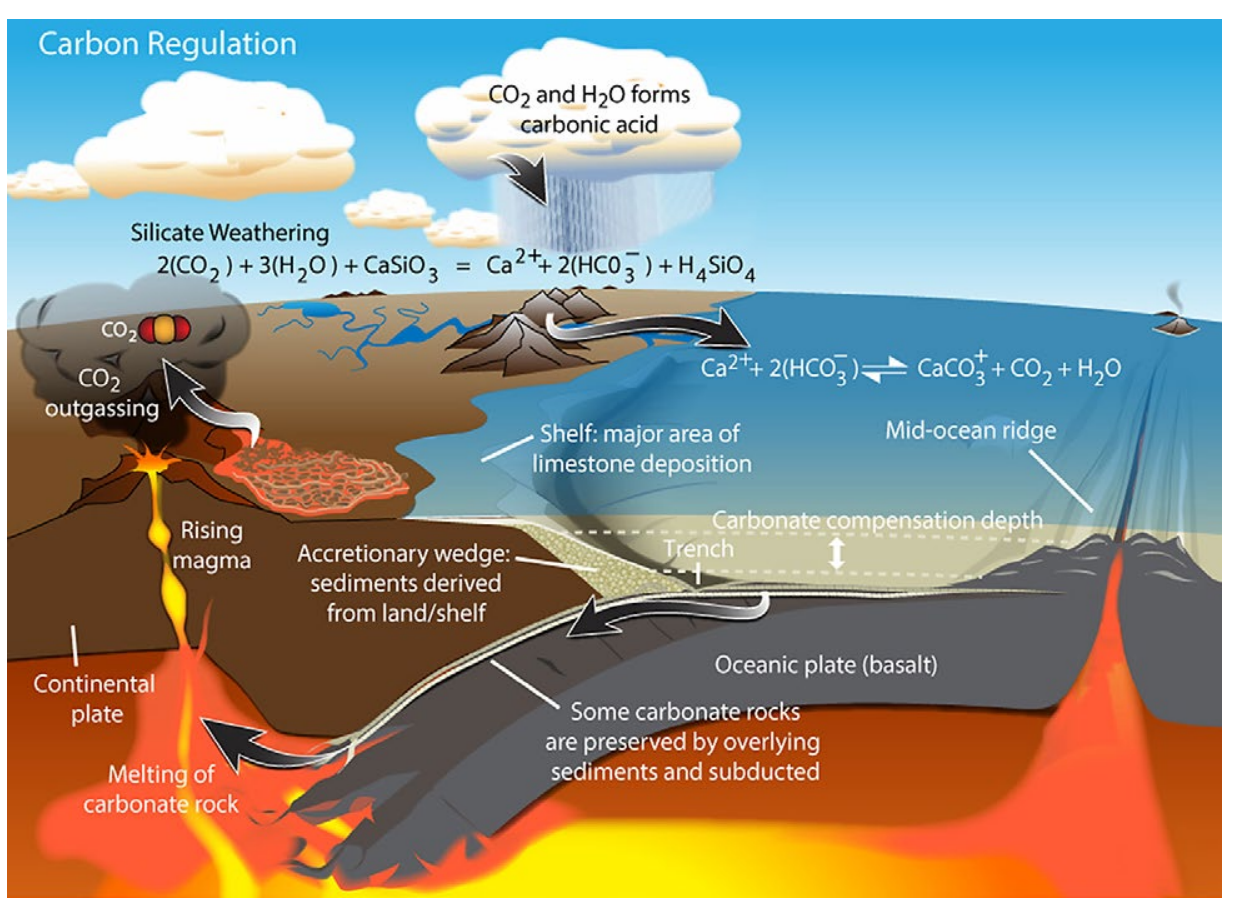

The carbonate-silicate cycle.
On geological time scales, chemical weathering of silicates consumes regulating the Earth's climate. The silicon released from rocks by chemica plants, as well aquatic organisms after thus impacting global photosynthesis. cycling shifts from a geochemical time, and that plants seem to be time scales, silicon-requiring diatoms (microalgae) in the oceans take up large amounts of carbon dioxide through photosynthesis. Effectively, the silicon leached from the land into the oceans controls the photosynthetically quatic organisms. Silicon is also a beneficial element for land plants.

During weathering of silicon-containing rocks, it is converted as dissolved silicon in soil solution, and available for plant uptake.

Soil processes cause the release of silicon into soil solution as monosilicic acid $\left(\mathrm{Si}(\mathrm{OH})_{4}\right)$. Plants can then take up monosilicic acid to produce phytoliths, the varied forms made of silica that are found in their leaves, stems and roots. These microscopic structures help to support the structural integrity of a plant. They also strengthen plants against stressors such as salty temperatures and they protect plants weathering is also taken up by land leaching out from soil into hydrosphere

Now, research is revealing that silicon process to biological control over the regulating factor. On biological
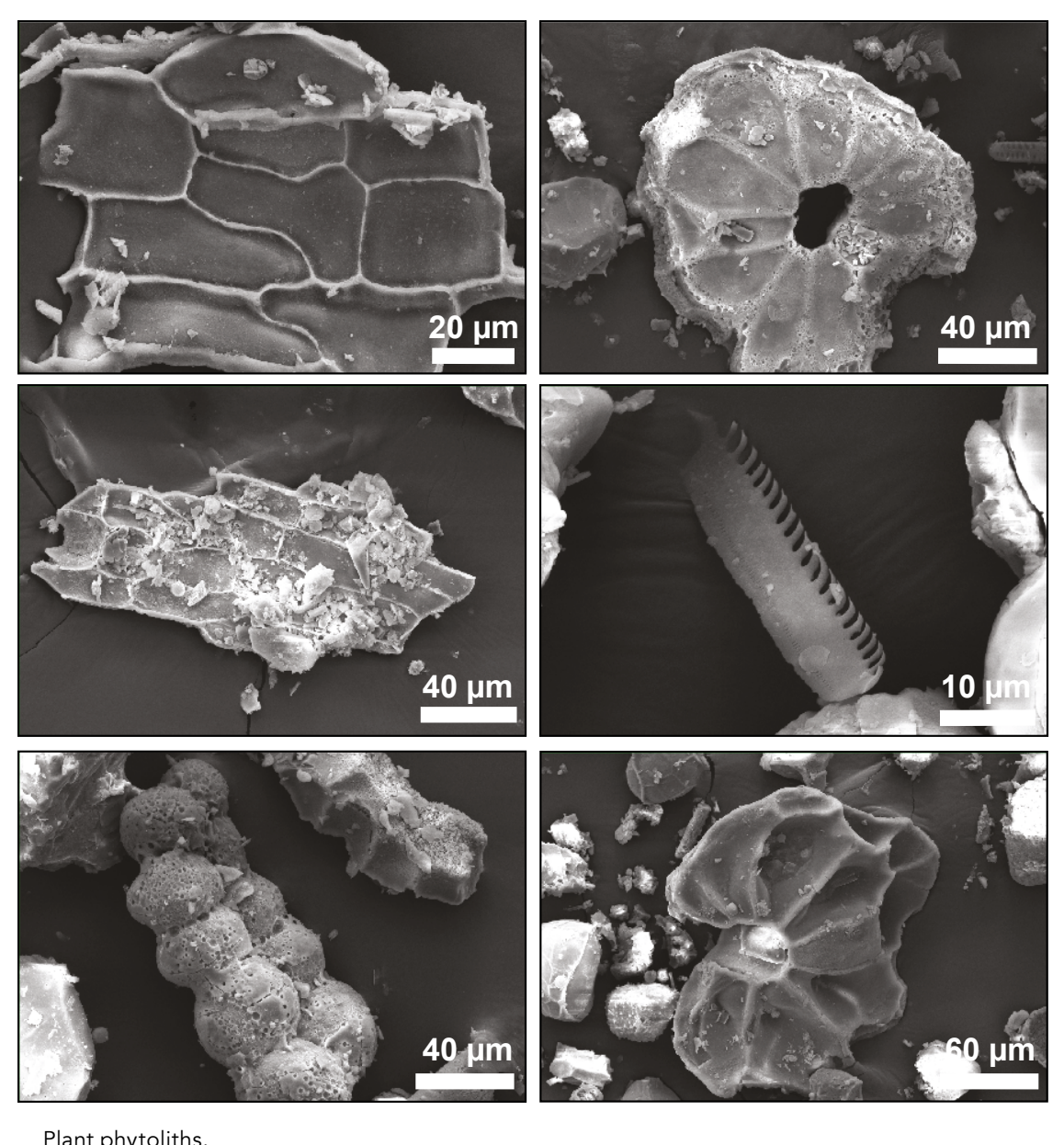

Plant phytoliths.

Silicon cycling shifts from a geochemical process to biological control over time, and plants seem to be the regulating factor.

from being eaten by herbivores (called herbivory) and from attacks by when plants die and decompose and this is where the biological aspect of silicon cycling comes in.

\section{GEOCHEMICAL VERSUS} BIOLOGICAL MECHANISM OF SILICON CYCLING As soils age, chemical weathering apparently becomes less important for supplying silicon to the biosphere, whil land plants have greater role. Plant phytoliths are much more soluble than mineral silicates, such that silicon release from plant decomposition is estimated to occur at higher rates compared to crystallne slicate mineral weathering. of geochemical versus biological mechanisms in the regulation of the of sil age has nycle as a function Neither is the dynamics of silicon in soil-plant systems during ecosystem development fully understood.

In two recent papers, de Tombeur and colleagues describe changes in the silicon cycle and its role in ecosystem development over long time periods. Using two unique soil chronosequences, they have been able to demonstrate the significance of soil age in regulating silicon cycling. Since soil silicon is derived ultimately from the parent rocks, plant-available sicon concentrations through desilication (silcon loss). This should increase the role of biological processes of silcon cycling as soils age

Soil formation is influenced by the mineral material from which it forms (called parent material), as well as by climate, topography, biotic factors and time. Soil chronosequences are obtained from sites that have developed over different periods of time with relatively small differences in other soil-forming factors. They can be used to study time as a factor soil formation as affected by place, environment and history. Since Westen Australia escaped the Pleistocene glaciations, it makes an ideal setting which to observe soil silicon changes over time.

\section{SOIL CHRONOSEQUENCES} SHED LIGHT ON THE PROCESS OF SOIL FORMATION

The researchers studied two soil

chronosequences from coastal dunes in the southwestern part of Australia that span over 2 million years - the full range of soil ages worldwide. These chronosequences include the oldest (most weathered and nutrient-depleted) solls in the world and the youngest of soils. The chronosequences also cepen carbonate lang secondary minerals, and the subsequent loss of these minerals through

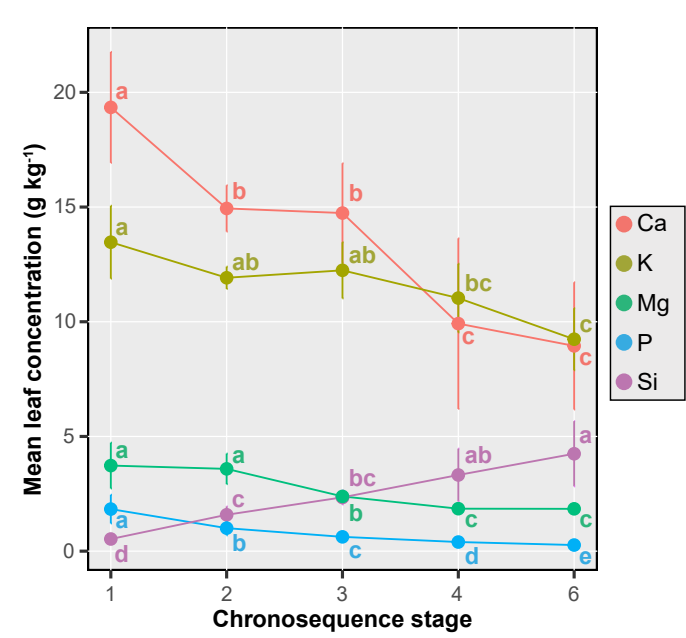

Investigating leaf nutrient concentrations tells us how soil physicochemical properties and pla us
community composition wary with soil plate 


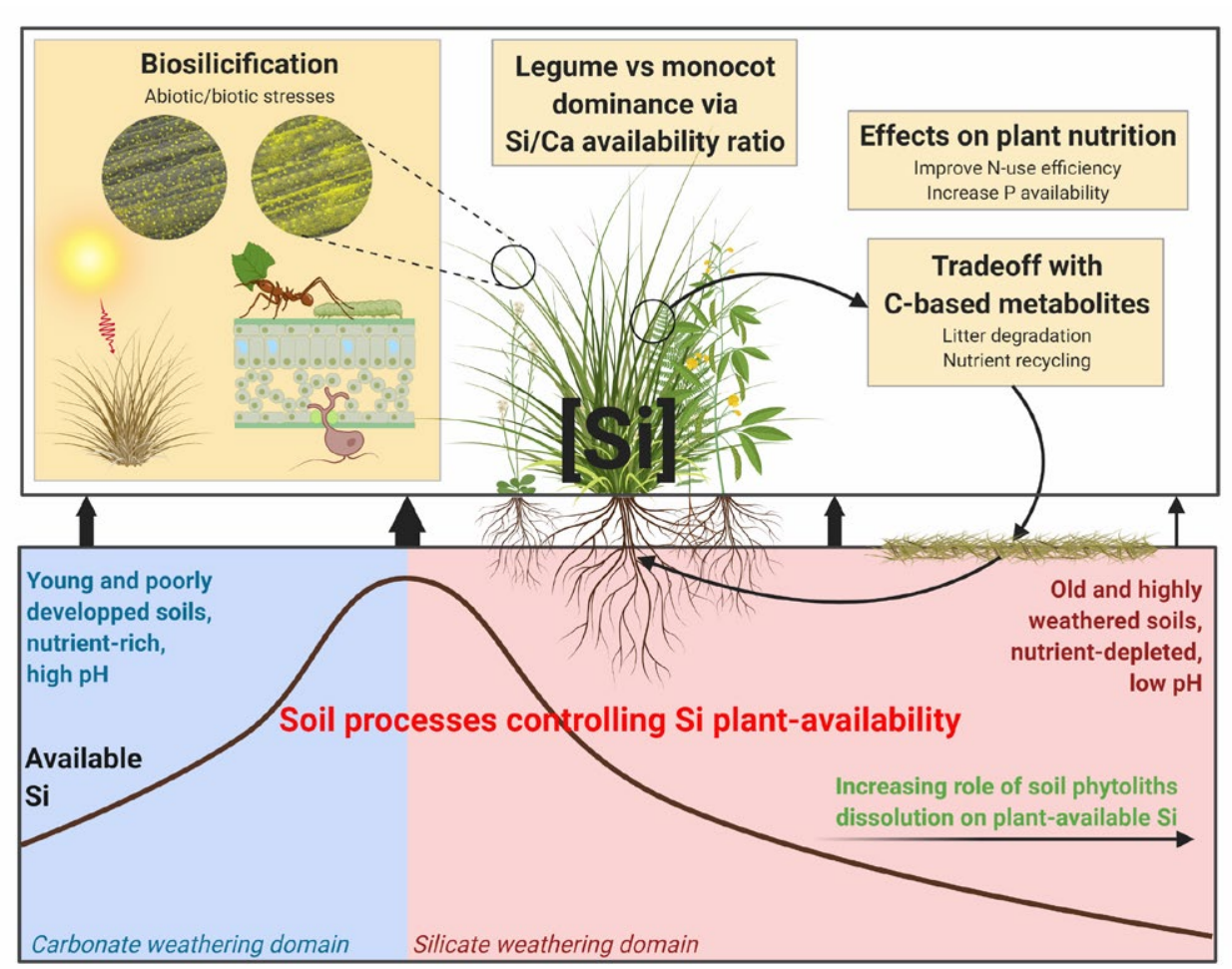

Schematic representation of soil processes controlling silicon availability across long-term
ecosystem development and potential implications.

dissolution and leaching. They are ideal for studying terrestrial biogeochemistry.

to be lowest in carbonate-rich, young Holocene soils; they were increased in

The research examined sol 位dle Pleistocent physiochemical poperies and looked quartz-rich soils (Early Pleistocene, at how silicon pools varied across the $\quad 2$ milion years ago). Soil phytoliths span of soil ages. Specific extractions their dissolution in the oldest soils. plant-available silicon was determined These results revealed a shift in the by extraction with $\mathrm{CaCl}_{2}$; the pool of source of silicon over time. Silicon adsorbed silicon was determined by availability was determined by

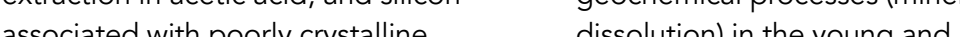

Soil age strongly impacts terrestrial silicon biogeochemistry, with potential cascading effects on ecosystem

functioning and global carbon cycle.

constituents and/or adsorbed onto sesquioxides was extracted using ammonium oxalate-oxalic acid. Finally, $\mathrm{Na}_{2} \mathrm{CO}_{3}$ extraction was used to estim the pool of silicon that included soil phytoliths.

In summary, they were able to monstrate that: the concentration of plant-available silicon were found intermediate-aged soils wh silicon as rock broke down, they contained less silicon, silicon-eapleng it away, br the deldest processes but rather by biological processes involving the recycling of
In the young soils, the researchers poin consumes protons and reduces weathering of silicate minerals; and also because silicon adsorption by secondary minerals is high in these alkaline soils. In the middle-aged soils, silicon availability increased with the loss of carbonates and the formatio of kaolinite (a clay mineral with the chemical composition $\mathrm{Al}_{2} \mathrm{Si}_{2} \mathrm{O}_{5}(\mathrm{OH})_{\text {. }}$ As mentioned earlier, in the oldest quartz-rich soils, it was the recycling of plant phytoliths that controlled silicon availability.

\section{THE ROLE OF SILICON IN}

TERRETRIAL ECOSYSTEMS

linear response of plant-available

silicon to long-term soil developm

or pedogenesis - its increase during

carbonate loss, then decrease during

quartz-enrichment - may have

important implications for the siliconrelated functioning of plants. It is likely to be reflected in plant performance and distribution because silicon reduces biotic and abiotic stresses and could also affect the dominance of legume or monocotyledonous plants in grass- and shrub-land ecosystems.

Changes in plant species composition across the sequence were also associated with increased plant silicon - but decreases in other important nutrients, such as calcium, magnesium, poaves. Dicotyledonous woody species ff the Proteaceae and Dilleniaceae contributed the greatest increase in foliar silicon on the oldest soils.

These findings point to a selective advantage for plants that accumulate silicon on nutrient-depleted soils. This accumulation could be because these adapted species produce longer-lived leaves and silicon accumulates with leaf age, but it may also reflect silicon-based plant functions. Silica deposition in the tissues of plants growing on the older, impoverished soils could have adaptive value in terms of plant anti-herbivore defence by minimising tissue loss and therefore increasing the persistence of nutrients in plants and the efficiency of

\section{Behind the Research}

Félix de

Tombeur

Dr Jean-Thomas

Cornelis

T. +32488273660 W: https://www.gembloux.ulg.ac.be/echanges-eau-sol-plante/felix-de-tombeur-assistant/ W: https://www.gembloux.ulg.ac.be/echanges-eau-sol-plante/jean-thomas-cornelis-2/

\section{Detail}

Avenue Maréchal Juin, 27 - Bât.52 5030 Gembloux

Belgium

Bio
Félix de Tombeur is a Teaching Assistant and PhD student at the University of Liege (Belgium). He combines expertise in soil science
and plant ecology and the use of and plant ecology and the use of soil the dynamics of silicon during longterm ecosystem development.

Jean-Thomas Cornelis is an Assistant Professor of Soil Science at the

University of Liege (Gembloux AgroBio Tech, Belgium) and earned his $\mathrm{PhD}$ at UCLouvain in Belgium in 2010. He will be joining the Faculty of Land and Food Systems at the University of British Columbia (Canada) in 2021. His research focuses on the study of soil processes that control the biogeochemical cycles of interactions respond to changes in the environmental drivers.

\section{Funding} FNRS (Fonds de la Recherche Scientiflque)

\section{References}

de Tombeur, F. et al. (2020) Plants sustain the terrestrial silicon cycle during ecosystem retrogression. Science science.abc0393

de Tombeur, F. et al. (2020) Silicon dynamics during 2 million years of soil development in a coastal dune Econ climate. Ecosystems https://doi.org/10.1007/s10021-020-00493-9

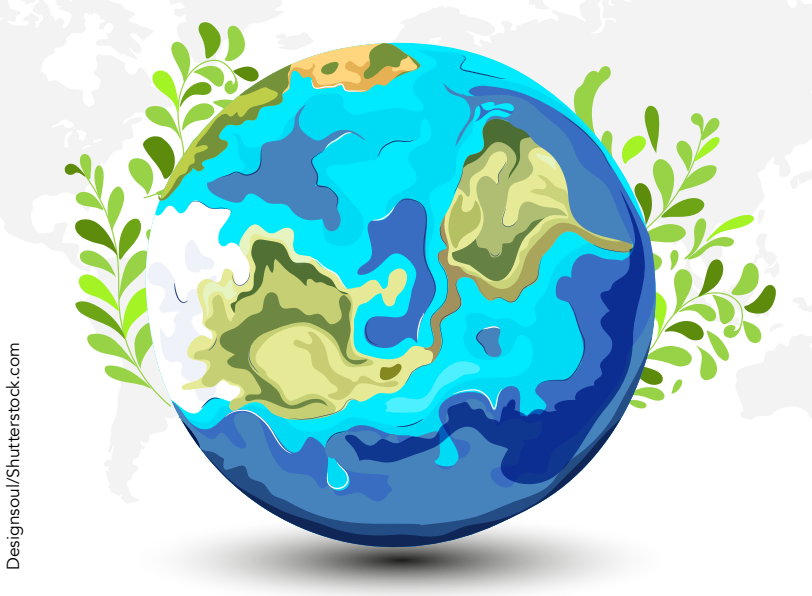

\section{Collaborators}

- ProfEtienne Laliberté (Université de The University of Western Australia)

Lambers (The University of Western Australia)

- Dr Benjamin L. Turner (Smithsonian Tropical Research Institute) Prof Gregory Mahy (University of

Liege)

-Prof Michel-Pierre Faucon (UniLaSalle) Western Australia)

\section{Personal Response \\ If plants have a role in regulating silicon availability, then human activities such as deforestation and important element. Would you like comment on this? II Indeed, it is true that human activities affect the terrestrial silicon cycling, with cascading effects on
the global carbon cycle. Research has already shown that fire, agriculture and shifts in land-use have a tremendous impact on silicon dynamics. Since climate is rapidly changing, evaluating its impact on silicon how climate affects terrestrial silicon cycle is central to our understanding of plant silicon-related functions, silicon fluxes to aquatic ecosystems, and ultimately the fixation of atmospheric carbon in terrestrial and
oceanic ecosystems.

LIÈGE université Gembloux Agro-Bio Tech 